\title{
Abductive Reasoning in Mathematics Education: Approaches to and Theorisations of a Complex Idea
}

\author{
David A Reid ${ }^{1 *}$ \\ ${ }^{1}$ University of Bremen, GERMANY
}

Received 28 March 2018 - Revised 18 May 2018 - Accepted 25 May 2018

\begin{abstract}
There is a growing literature on the importance of abductive reasoning in mathematics education. However, there are some important variations in what exactly is referred to as 'abductive reasoning'. This article identifies key theorisations of abductive reasoning in the work of Peirce, Habermas and Eco, as well as describing different approaches to abductive reasoning found the mathematics education literature. A framework in which the different approaches taken in the research literature can be placed and compared is proposed.
\end{abstract}

Keywords: abductive reasoning, conjecturing, function of reasoning, logical form, proof and proving

\section{INTRODUCTION}

There is a growing literature on the importance of abductive reasoning in mathematics education (e.g., Cifarelli, 1999; Krummheuer, 2007; Pedemonte, 2007; Pedemonte \& Reid 2011; Rivera \& Becker, 2007; Weber, Maher, Powell, $\&$ Lee, 2008). However, there are some important variations in what exactly is referred to as 'abductive reasoning'. This chapter will explore the origins of the concept of abductive reasoning, identify the most significant approaches in mathematics education literature that refers to abductive reasoning, and propose a framework in which the different approaches taken in the research literature can be placed and compared.

\section{THEORISATIONS OF ABDUCTIVE REASONING}

The current usages of the words "abduction" and "abductive" (in logic) are due to Charles Saunders Peirce. Peirce offers several fundamentally different descriptions of abduction, as his thinking evolved over time. In this section I review the different descriptions Peirce gives and try to organise them. I will also include ideas from Habermas and Eco, who have also examined Peirce's concept of abduction and made useful distinctions between types of abduction.

\section{ABDUCTIVE REASONING IN THE WORK OF PEIRCE}

Peirce's ideas related to abduction evolved over time, and so it is impossible to give a definite definition of abduction 'according to Peirce'. While some authors (e.g., Meyer, 2010) limit themselves to Peirce later work, presumably considering it more conclusive, I find there are useful insights in all Peirce's work, and so I will provide a thorough overview here. Furthermore, as will be seen later, researchers in mathematics education also make use of Peirce's ideas, including some from very early in his work on abduction, and so to understand approaches to abductive reasoning in mathematics education one must consider more than Peirce's later work.

Fann (1970) claims that "most writers on Peirce's theory of abduction divide Peirce's thought roughly into two periods" (p. 9) but that they disagree on the borderline between these two periods. I prefer to make a distinction according to whether Peirce's description of abduction refers primarily to the logical form of the reasoning or to the functions addressed by reasoning, and I will organise my comments here according to this distinction. It is also

(C) 2018 by the authors; licensee Modestum Ltd., UK. This article is an open access article distributed under the terms and conditions of the Creative Commons Attribution License (http://creativecommons.org/licenses/by/4.0/). $\square$ dreid@uni-bremen.de ( ${ }^{*}$ Correspondence) 


\section{Contribution of this paper to the literature}

- It identifies key theorisations of abductive reasoning in the work of Peirce, Habermas and Eco.

- It describes the full range of different approaches to abductive reasoning found the mathematics education literature.

- It proposes a framework in which the different approaches taken in the research literature can be placed and compared.

possible to make a further distinction among descriptions referring to logical form according to the specificity of the reasoning, and I will discuss this where it is relevant.

\section{Theorisations based on the Logical Form of the Reasoning}

Peirce's first discussion of abduction seems to be his presentation in 1867 to the American Academy of Arts and Sciences. At that time he referred to abduction as "Hypothesis" and characterised it by this syllogism (1867, p. 285; CP 2.5111):

$$
\begin{gathered}
\text { Hypothesis } \\
\text { Any } M \text { is, for instance, } P^{\prime} P^{\prime \prime} P^{\prime \prime \prime} \text {, etc. } \\
S \text { is } P^{\prime} P^{\prime \prime} P^{\prime \prime \prime} \text {, etc.; } \\
\therefore S \text { is probably } M .
\end{gathered}
$$

Here $S$ is the subject, a specific case of interest, and $P^{\prime}, P^{\prime \prime}, P^{\prime \prime \prime}$ are a number of characteristics of $S$. The word "probably" in the conclusion indicates a key characteristic of abduction. The argument gives the conclusion plausibility, but not certainty. The only exception to this occurs when the list $P^{\prime}, P^{\prime \prime}, P^{\prime \prime \prime}$ of characteristics is exhaustive, in which case Peirce calls the argument "formal hypothesis" or "reasoning from definition" (1867, p. 282; CP 2.508). In this early form, abduction concerns a general rule (it applies to any $M$ ) and a specific subject. The conclusion is about $S$, the specific case.

In an article published in Popular Science Monthly in 1878, Peirce gives an example involving white beans, and uses the terms 'rule', 'result' and 'case' to refer to the three elements of an abduction.

$$
\begin{aligned}
& \text { Suppose I enter a room and there find a number of bags, containing different kinds of beans. On the } \\
& \text { table there is a handful of white beans; and, after some searching, I find one of the bags contains white } \\
& \text { beans only. I at once infer as a probability, or as a fair guess, that this handful was taken out of that } \\
& \text { bag. This sort of inference is called making an hypothesis. It is the inference of a case from a rule and a } \\
& \text { result. (1878, p. 471-472; CP 2.623) }
\end{aligned}
$$

Peirce presents this example also as a syllogism:

$$
\begin{gathered}
\text { HYPOTHESIS. } \\
\text { Rule. - All the beans from this bag are white. } \\
\text { Result. - These beans are white. } \\
\therefore \quad \text { Case. }- \text { These beans are from this bag. (1878, p. 472; CP 2.623) }
\end{gathered}
$$

The differences between this formulation and Peirce's formulation of 1867 are slight, but significant. Instead of the subject $S$ "these beans" sharing a number of characters, only one character "being white" is involved in this canonical example. This suggests that Peirce saw abduction as possible on very limited evidence. It is also possible to see the result in this case as referring to more than a specific case. "These beans are white" could be phrased as "All the beans in this sample are white," which has the same generality as "All the beans from this bag are white". The original 1867 formulation suggests that abduction is the inference of a specific case from a general rule and a specific result. The 1878 formulation suggests that abduction is the inference of a specific or general case from a general rule and a specific or general result. Thus the 1878 formulation can be applied in more situations, involving both specific and general results and perhaps very limited evidence.

In 1883 Peirce published his essay "A Theory of Probable Inference" in the Johns Hopkins Studies in Logic in which he describes abduction in a similar way:

Hypothesis proceeds from Rule and Result to Case; it is the formula of the acquirement of secondary sensation - a process by which a confused concatenation of predicates is brought into order under a synthetizing predicate. (1883, p. 145; CP 2.712) 
However, in presenting Hypothesis as a syllogism, he makes an attempt to indicate the degree of probability that the specific case $S$ belongs to the class $M$.

\section{Hypothesis.}

$M$ has, for example, the numerous marks $P^{\prime}, P^{\prime \prime}, P^{\prime \prime \prime}$, etc.,

$S$ has the proportion $r$ of the marks $P^{\prime}, P^{\prime \prime}, P^{\prime \prime \prime}$, etc.;

Hence, probably and approximately, $S$ has an $r$-likeness to $M$. (1883, p. 140; CP 2.706)

About this formulation Peirce later commented:

But in my paper on Probable Inference in the Johns Hopkins "Studies in Logic," owing to the excessive weight I at that time placed on formalistic considerations, I fell into the error of attaching a name[,] the synonym I then used for Abduction, to a probable inference which I correctly described, forgetting that according to my own earlier and correct account of it, abduction is not of the number of probable inferences. It is singular that I should have done that, when in the very same paper I mention the existence of the mode of inference which is true abduction. Thus, the only error that paper contains is the designation as Abduction of a mode of induction somewhat resembling abduction, which may properly be called abductive induction. (1902a)

According to my own principles, the reasoning with which I was there dealing could not be the reasoning by which we are led to adopt a hypothesis, although I all but stated as much. But I was too much taken up in considering syllogistic forms and the doctrine of logical extension and comprehension, both of which I made more fundamental than they really are. As long as I held that opinion, my conceptions of Abduction necessarily confused two different kinds of reasoning. (1902b; CP 2.102)

Between 1883 and 1902 occurs the borderline often claimed between the two periods of Peirce's work on abduction. One marker is a change of terminology, as Peirce begins to refer to abduction as either 'abduction' or 'retroduction' reserving the word 'hypothesis' for a conjecture. As suggested by the two quotes above, at this time he also came to see syllogisms as less fundamental, and as a result it becomes more difficult to identify the logical form of abductive reasoning in his later writing. Instead there is more emphasis on the functions addressed by reasoning (see below). It would be a mistake, however, to see this division too starkly. Peirce was interested in the functions addressed by reasoning from the beginning and had in mind a specific logical form for abduction even if this is hard to discern in his later writings.

In 1896, in a manuscript entitled "The Logic of Mathematics; an Attempt to Develop my Categories from within", Peirce introduced the term 'retroduction' to refer to abduction, and used 'hypothesis' to mean "something, which looks as if it might be true and were true and which is capable of verification or refutation by comparison with facts" (CP 1.120). The nature of this hypothesis is somewhat unclear. Peirce offers two examples. In the first (CP 1.68) he notes that it has not been possible to decompose hydrogen (and the other elements) in spite of various efforts to do so. This is the result. The rule in this case is that elements cannot be decomposed, and we abduce the case that hydrogen is an element. In the second example he discusses Kepler's discovery of the laws governing the motions of the planets, and seems to suggest that Kepler hypothesised a series of general rules that would lead to the observed results, arriving in the end at a new general rule that had not previously existed. So the Rule is abduced as well as, or instead of, the Case. One could read the Kepler example as including two different kinds of abduction. Concerning the shape of the orbits of the planets, Kepler (presumably) was limited to closed curves familiar from geometry, circles, ellipses, ovoids, etc. He selected a Rule relating the shape of the orbit to the position of the planet, arriving at the abduction:

The observed positions of the planets are $\mathrm{P}$,

If the shape of the orbits is an ellipse then the positions of the planets are P;

Therefore, the shape of the orbits is an ellipse.

This fits the logical form of 1878. However, in discovering the other laws, Kepler did not have a limited set of pre-existing possibilities to select from, for example concerning the relationship between the speeds of the planets and their positions. So he must have abduced the Rule as well as the Case.

The only explicit representation of logical form for abduction that I am aware of in Peirce's later writing is in his "Lectures on Pragmatism" (1903, CP 5.14-212) where he presents the abductive form of inference in this way:

The surprising fact, $C$, is observed;

But if A were true, C would be a matter of course,

Hence, there is reason to suspect that $A$ is true. (1903; CP 5.189) 
At first sight this form is not much different from that of 1878 . The result $\mathrm{C}$ can be specific or general, as can the case A. One change is that the result is stated before the rule. If the Case A is inferred from both the Result C and the Rule, then there is no significant difference from the form of 1878. This is how Fann (1970) interprets this logical form, and interestingly, he changes the punctuation when he quotes it (p. 52), replacing the comma at the end of the second line with a semicolon. The original punctuation (assuming the editors of the Collected Papers did not change it from Peirce's version) supports an alternative interpretation. The semicolon ending the first line could be read as dividing the syllogism there, so that both the Rule and the Case are inferred from the Result. If this was Peirce's intent then he seems to be describing something like the reasoning involved in Kepler's discovery of the laws governing the motions of the planets (see above) in which both the Case and the Rule are abduced.

\section{Theorisations based on the Functions Addressed by Reasoning}

Peirce considers not only the logical from of abduction but also what it is used for, its function, especially in scientific work. He identifies two different functions for abduction, explaining a fact and exploring to discover something new.

In his article published in Popular Science Monthly in 1878, alongside the 'white beans' example of the logical form of abduction, Peirce also noted the importance of explaining a surprising fact as the function of abduction. Recall that at this stage Peirce calls abduction 'hypothesis'. "Hypothesis is where we find some very curious circumstance, which would be explained by the supposition that it was a case of a certain general rule, and thereupon adopt that supposition." (1878, p. 472; CP 2.624).

An important characteristic suggested by Peirce's 1896 use of 'hypothesis' to mean "something, which looks as if it might be true and were true and which is capable of verification or refutation by comparison with facts" (CP 1.120 ) is that the conclusion of an abduction should be "capable of verification or refutation by comparison with facts." This means that accounting for a surprising occurrence by making reference to a mysterious force which may never again have any effect, does not count as an abduction. So in addition to being explanatory, the hypothesis must also be testable.

From about 1901 (e.g., CP 6.5252) Peirce began to use the term 'abduction' instead of 'retroduction' or 'hypothesis', although he sometimes reverts to his earlier terms. He usually uses 'hypothesis' to mean a supposition that arises through abduction.

\section{The first starting of a hypothesis and the entertaining of it, whether as a simple interrogation or with any degree of confidence, is an inferential step which I propose to call abduction ... I call all such inference by the peculiar name, abduction, because its legitimacy depends upon altogether different principles from those of other kinds of inference. (CP 6.525)}

In his 1903 "Lectures on Pragmatism" Peirce writes "Abduction is the process of forming an explanatory hypothesis. It is the only logical operation which introduces any new idea" (CP 5.171). Here we see that it is not only the explanatory value of the hypothesis that is important, but also its newness. This suggests that all discovery must occur through abduction. "If we are ever to learn anything or to understand phenomena at all, it must be by abduction that this is to be brought about." (CP 5.171). Here the emphasis is on exploring to discover, in addition to explanation.

\section{ABDUCTIVE REASONING AND HABERMAS}

Habermas $(1987,1968)$ provides a summary of Peirce's ideas on abduction and makes a distinction between the two different functions for abduction discussed above. According the Habermas "Under the term 'abduction' ...Peirce subsumes two different processes without clearly distinguishing between them" (1987, p. 115, note 4). Habermas relates the two functions to two different logical forms.

Sometimes [Peirce] understands by abduction only the employment of a lawlike hypothesis for the end of causal explanation: here we infer from a result to a case with the aid of a valid rule. This inference leads to an explanatory hypothesis, which can then be tested. (p. 115, note 4)

Here Habermas associates the function of explanation with the logical form described by Peirce in 1878. From a Result and a Rule we infer a Case. The second function of abduction, discovery, has a different logical form:

Starting with a (surprising) result, we search for a rule with whose aid we can infer the case: the rule itself, therefore, is not yet assumed as valid. Thus the representation of abduction as inference from a rule (as major premise) and a result (as minor premise) to the case (as conclusion) is not quite accurate here. For the major premise is what is arrived at. ( $p .115$, note 4$)$ 
The logical form of a discovery is: a Rule is inferred from a Result and a Case. This form of abduction Habermas calls a 'non-inductive generalisation'.

Starting with an empirical regularity given with a case and result, we search for a lawlike hypothesis from which one of the two variables can be derived by means of the other. Then "we have a kind of mixture of induction and hypothesis supporting one another; and of this kind are most of the theories of physics" [1878, p. 480; CP 2.640] (p. 115, note 4).

Habermas quotes Peirce further:

The great difference between induction and hypothesis is, that the former infers the existence of phenomena such as we have observed in cases which are similar, while hypothesis supposes something of a different kind from what we have directly observed, and frequently something which it would be impossible for us to observe directly. Accordingly, when we stretch an induction quite beyond the limits of our observation, the inference partakes of the nature of hypothesis. It would be absurd to say that we have no inductive warrant for a generalisation extending a little beyond the limits of experience ... Yet, if an induction be pushed very far, we cannot give it much credence unless we find that such an extension explains some fact which we can and do observe. (1878, p. 480; CP 2.640)

This logical form, a Rule is inferred from a Result and a Case, is the same as that given by Peirce in the same article to induction. Peirce he writes explicitly "induction is the inference of the rule from the case and result" (1878, p. 471; CP 2.622). However, in the passages quoted by Habermas above, Peirce seems to be saying that abduction can have the same logical form, but that abduction goes beyond observation.

\section{ABDUCTIVE REASONING IN THE WORK OF ECO}

Eco (1983) also considers different variants of the logical form of abduction, specifically related to the nature of the rule. Eco identifies three kinds of abduction: overcoded, undercoded and creative (see also Bonfantini \& Proni, 1983, and Magnani, 2001, for related classifications). Overcoded abduction occurs when the arguer is aware of only one rule from which that case would follow (p. 206). It is the same as Peirce's 1878 formulation.

If there is more or less than one rule known to the arguer, then the situation becomes more complex. Before the case can be inferred a rule must be found and the conclusion of the abduction will depend on what that rule is. As Eco points out, "the real problem is ... how to figure out both the Rule and the Case at the same time, since they are inversely related, tied together by a sort of chiasmus" (p. 203).

If there are multiple general rules to be selected from, Eco calls it "undercoded abduction" (p. 206). Eco uses Peirce's Kepler example to illustrate this, arguing that as the number of closed curves that are possible paths for a moving object is not infinite, Kepler was selecting from among several possibilities (circle, ellipse, ovoid, etc.).

Magnani (2001) links overcoded and undercoded abductions together as selective abductions. Selective abduction is defined as the process of finding the right explanatory hypothesis from a given set of possible explanations. In this case, the arguer should find the most appropriate rule to construct the conclusion from among the set of rules he has access to.

Peirce himself refers to the possibility of selecting from several possible rules:

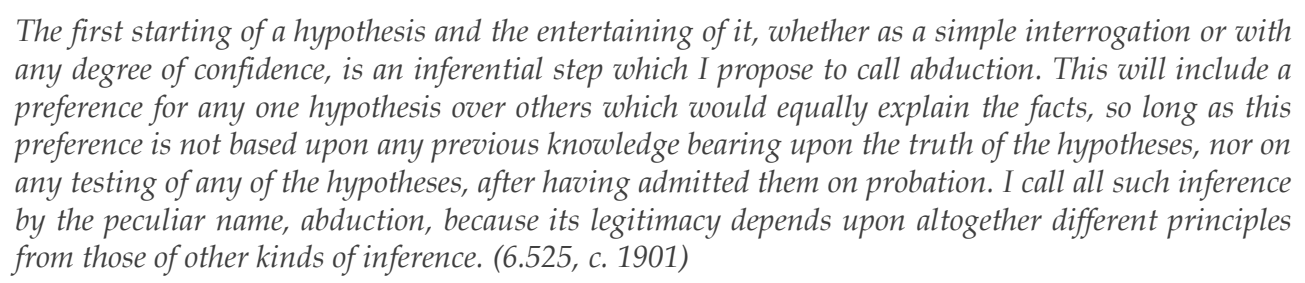

Both overcoded and undercoded abduction can explain a surprising result. But sometimes there is no known rule that would produce the observed result. Thus the arguer must discover or invent a new rule. Eco (1983) calls an abduction that involves the invention of a new rule a "creative abduction". This is similar to Habermas' "noninductive generalisation" in that a Rule is inferred, but in non-inductive generalisation a Rule is inferred from a Result and a Case, as in an induction. In a creative abduction, however, the only premise of the abduction is the Result, and both the Rule and the Case are consequences of it. This fits the alternative interpretation of the 1903 logical form discussed above, as well as my second interpretation of the Kepler example (above). 
Table 1. Summary of logical forms and functions of abduction in Peirce, Habermas and Eco

\begin{tabular}{cccc}
\hline Date & Logical Form & Function & Notes \\
\hline 1867 & Rule, Result, imply Case & not specified & $\begin{array}{c}\text { Specific Result and Case, Case has a number of } \\
\text { significant characteristics }\end{array}$ \\
\hline 1878 & Rule, Result, imply Case & explaining a "curious circumstance" & $\begin{array}{c}\text { Possibly general Result and Case, Case has a single } \\
\text { significant characteristic Eco's overcoded abduction }\end{array}$ \\
\hline 1878 & Case, Result, imply Rule & explaining a "curious circumstance" & $\begin{array}{c}\text { Logical form not explicitly given, Habermas' } \\
\text { explanatory abduction. }\end{array}$ \\
\hline 1883 & $\begin{array}{c}\text { Rule, Result partly } \\
\text { matching rule, imply Case }\end{array}$ & $\begin{array}{c}\text { Logical form later rejected as confused with a kind of } \\
\text { induction }\end{array}$ \\
\hline 1896 & Rule, Result, imply Case & explanation must be testable & $\begin{array}{c}\text { Logical form not explicitly given, inferred from } \\
\text { "elements" example }\end{array}$ \\
\hline $\begin{array}{c}1896 \\
1901\end{array}$ & $\begin{array}{c}\text { Result, implies new Rule, } \\
\text { Case }\end{array}$ & $\begin{array}{c}\text { explanation must be testable } \\
\text { a preference for any one } \\
\text { hypothesis over others which } \\
\text { would equally explain the facts }\end{array}$ & $\begin{array}{c}\text { Logical form not explicitly give, inferred from 'Kepler' } \\
\text { example. Eco's creative abduction. }\end{array}$ \\
\hline $1903 ?$ & Result, Rule, imply Case & $\begin{array}{c}\text { discovering a new idea, which is } \\
\text { also an explanation }\end{array}$ & $\begin{array}{c}1903 \text { logical form, Fann's (1970) interpretation. } \\
\text { Similar to 1878, but Result and Rule in reverse order. }\end{array}$ \\
\hline $1903 ?$ & Result, implies Rule, Case & $\begin{array}{c}\text { discovering a new idea, which is } \\
\text { also an explanation }\end{array}$ & $\begin{array}{c}1903 \text { logical form, alternative interpretation. Eco's } \\
\text { creative abduction. }\end{array}$ \\
\hline
\end{tabular}

\section{SUMMARY}

As outlined above, in Peirce's work the characterisation of abduction evolves over time. This evolution is summarised in Table 1.

In his early work the focus is on the logical form, which is usually a Result and a Rule implying a Case. There is some variation on the specificity of the Case involved, as least in the examples given. There are also variation in the logical form itself implied by some of the examples Peirce gives. Both in the example of Kepler's work (in 1896) and in (1878; CP 2.640) Peirce suggests that the outcome of an abduction could be the Rule, either in combination with the Case, or alone as an implication of both the Result and the Case, with the same logical form as induction. Eco provides a classification that makes this distinction clearer, describing abductions that lead to a Rule as 'creative'. Habermas also describes at least the second type in which the Rule is implied by the Result and the Case, calling it 'non-inductive generalisation'.

In Peirce's later work he rarely describes the logical form of abduction explicitly, and emphasises instead the function of an abduction. This characterisation also evolves. In early work (from 1878) Peirce stresses the function of abduction in explaining a surprising result. Later (1896) he adds that this explanation should be open to empirical refutation; there should be the possibility to test it. Still later (at least by 1903) he focusses on the function of abduction in generating new knowledge, giving it a central role in the process of scientific exploration and discovery. Habermas distinguishes the first and the last of these functions as explanatory abduction and innovative abduction.

\section{APPROACHES TO ABDUCTIVE REASONING IN MATHEMATICS EDUCATION}

Any discussion of abductive reasoning in mathematics education is complicated by the multiple ways in which the concept is used. Abductive reasoning can be employed in methodological discussions, as part of a theory of learning, to describe problem solving processes, and in connection with deductive proving. In this section I provide a brief overview of these different usages, as a way of orienting the reader to the problématique addressed by the framework I will introduce later. Three 'lineages' can be identified in the mathematics education literature. One (predominantly German) lineage begins with Voigt's work on methodology and leads to Hoffmann's use of abductive reasoning in a theory of learning. A second (based in the United States) focusses on abductive reasoning in problem solving. A third (mainly Italian) lineage focusses on the role of abductive reasoning in the 'cognitive unity' between conjecturing and proving.

\section{ABDUCTIVE REASONING IN METHODOLOGY}

Perhaps the earliest mention of abductive reasoning in mathematics education research is Voigt's (1984) use of Peirce's description of abductive reasoning in his discussion of his approach to researching classroom interactions. Voigt cites directly Peirce's early (c. 1878) description of abduction in terms of a syllogism as well as aspects related 
to the functions of abductive reasoning outlined in Fann (1970), and also Habermas's $(1968,1987)$ distinction between explanatory and innovative abductions. Peirce's emphasis on abduction as producing a new general rule as an "explanatory hypothesis" to explain observed data is of central importance to Voigt's methodological discussion, as he is seeking to justify the generation of such hypotheses in his own research.

Voigt's work is cited by other researchers as a source of their methodological ideas. Beck and Jungwirth (1999), for example, cite Voigt as well as Peirce's (c. 1903) description of abduction as explaining a "surprising fact". They write:

\begin{abstract}
Abduction allows one to construct a new general rule that can explain an unexpected event or unexplained aspects of an otherwise known phenomenon. One tries to formulate new rules provisionally, under whose hypothetical validity the surprising event becomes plausible. (Beck $\mathcal{E}$ Jungwirth, 1999, p. 246, my translation)
\end{abstract}

The work of Krummheuer (e.g., 2007) also falls into the tradition. Krummheuer starts his methodological considerations with Peirce's 1903 characterisation of abduction as "explanatory hypothesis" fundamental to the theoretical development of science.

\title{
ABDUCTIVE REASONING AS PART OF A THEORY OF LEARNING
}

Hoffmann (2001) develops a theory of learning in which signs mediate between different forms of knowledge, which makes learning possible. Essential in this process is that the learner become aware of the rules of the systems of signs in play, and Hoffmann considers that this becoming aware occurs through abduction.

From the point of view of the semiotic learning theory developed here, systems of representation and signing are at best only instruments of learning if they have a regularity beyond our subjective conditionality. According to the theory sketched out here, it is the core of learning processes to develop such regularities in a process of diagrammatic abductive inference. (p. 248, my translation4)

While Hoffmann uses Peirce's work for a different purpose, he is aware of the work of Voigt (2000), Beck and Jungwirth (1999) and Brandt and Krummheuer (2000). Hoffman, however, makes much wider use of original sources and has carefully considered the evolution of Peirce's ideas (see Hoffmann, 1999). Hoffmann focusses on the function of abduction in explaining surprising facts, and especially in discovering new ideas. These functions are much more important for Hoffmann's theory than the logical form of abduction, though Hoffmann does quote the form Peirce presented in 1903:

The surprising fact, $C$, is observed; But if A were true, C would be a matter of course, Hence, there is reason to suspect that $A$ is true (para. 189; CP 5.189).

Hoffmann's main emphasis however, is on the nature of $\mathrm{C}$ as a "surprising fact" and of $\mathrm{A}$ as a new idea.

\section{ABDUCTIVE REASONING IN CONJECTURING WHEN SOLVING PROBLEMS}

Cifarelli and Sáenz-Ludlow are interested in problem solving, and specifically activities in which a learner needs to discover mathematical coherences to solve the problem. In a series of studies they discuss examples of abductive reasoning playing a mediating role in problem solving activity (Cifarelli \& Sáenz-Ludlow, 1996), distinguish two different kinds of abductions in the mathematical activity of a learner (Sáenz-Ludlow, 1997), analyse ways abductive reasoning structures problem solving activity (Cifarelli, 1997a) and transforms problem solving situations (Cifarelli, 1997b), and explain ways in which abductive reasoning fosters an intermingling of problem posing and problem solving activities (Cifarelli, 1999).

Cifarelli rarely cites Peirce directly, making use instead of secondary sources (primarily Fann, 1970). He offers only brief descriptions of abduction, but those suggest that he is mainly focussed on the function of abduction, which "furnishes the reasoner with a novel hypothesis to account for surprising facts" (1999, p. 217). Sáenz-Ludlow makes use of a wider range of secondary sources, as well as citing Peirce directly. Like Cifarelli, she focusses on the function of abduction as "accounting for observed facts" (Sáenz-Ludlow, 1997, p. 120) and generating a novel hypothesis. She also quotes Peirce's logical form of 1903, but places no great emphasis on it.

Ferrando (2006) attempted to analyse students' problem solving in calculus using Peirce's 1903 logical form of abduction its function as a means to explain a surprising fact. She encountered some limitations of this framework for her purposes, and inspired by Cifarelli's (1999) idea "that an abductive inference may serve to organise, reorganise, and transform a problem solver's actions" (Ferrando, 2006, p. 58), she elaborates a broader typology of abductive processes, which she refers to as the "Abductive System". "I define the Abductive System as being a set 
whose elements are: facts, conjectures, statements, and actions" (p. 58). Both statements and actions can be abductive. "An abductive statement is a proposition describing a hypothesis built in order to corroborate or to explain a conjecture." (p. 59). "An abductive action represents the creation, or the 'taking into account' a justifying hypothesis or a cause" (p. 59).

Though Ferrando was aware of Peirce's earlier work on abduction, as she cites the 1878 'beans' syllogisms in (2000), she make use primarily of the 1903 logical form and the function of explaining.

\title{
ABDUCTIVE REASONING IN THE DIALECTIC BETWEEN CONJECTURING AND PROVING
}

Abductive reasoning is important in connection with the idea of 'cognitive unity' employed in the work of a number of mathematics education researchers. Cognitive unity was proposed first as a hypothesis by Boero, Garuti, Lemut and Mariotti (1996). They proposed that the argumentation processes involved in first forming a conjecture involve elements that are then employed in the proof of the conjecture, so that the two processes of conjecturing and proving have a unity. In their first paper on cognitive unity Boero, Garuti, Lemut and Mariotti do not mention abductive reasoning explicitly. However, they write:

\begin{abstract}
The production of a conjecture ... can be considered as a "hypothesis" production act: that is to say, it can consist of the argumented selection ... among possible alternatives, with a margin of uncertainty, as to its validity, that can be solved through the systematically organised reasoning or a counterexample ("verification" of the "hypothesis"). (p. 114)
\end{abstract}

This description is suggestive of undercoded abduction and reminiscent of Peirce's c. 1901 comments quoted above (from (6.525)).

Arzarello, Micheletti, Olivero and Robutti (1998a,b) seem to have been the first to explicitly link abductive reasoning to cognitive unity, though they mention 'cognitive unity' only as a possible label for the cognitive continuity they describe between conjecturing and proving. In (1998a) they describe the explorations of a student solving a geometric problem. At one point the student hypothesises that he might be able to apply Varignon's theorem to solve the problem. Having selected this Rule, he conjectures a Case (an outer parallelogram) that would produce the desired Result (a rectangle). The making of this hypothesis is described as abductive, and Arzarello, Micheletti, Olivero and Robutti reference Peirce (explicitly the logical form of 1878). The student later reverses the abduction, proving that if one begins with a parallelogram, by Varignon's theorem, the desired configuration is obtained. This reversing of the abduction using is conjecturing to produce the deduction used in proving is given by Arzarello, Micheletti, Olivero and Robutti as an example of the cognitive continuity between conjecturing and proving. In (1998b) they provide a similar example and make the same reference to Peirce.

Arzarello, Andriano, Olivero and Robutti (1998) also discuss "the dialectic between an explorative, groping phase and an organising strategy which converges towards some piece of validated knowledge." (p. 78). They write:

In this paper we show that abduction, in the sense described in Peirce's Logic (Peirce [1878; CP 2.6192.644]) plays an essential role in this dialectic: abduction reveals to be an essential resolutive move, after which the conjectures are formulated and allows the transition to the proving modality, which remains in any case deeply intertwined with it. This is partially in conformity with Peirce's claim that of the three logic operations, namely deduction, induction, abduction (or hypothesis), the last is the only one which introduces any new idea (Peirce [1903, CP] 5.171). (p.78)

Arzarello and his coauthors usually refer to the 1878 logical form of abduction and its function of introducing a new idea in their later work (e.g., Arzarello, Olivero, Paola \& Robutti, 2002; Arzarello \& Sabena, 2011).

Boero, Garuti and Lemut (1999), two of the originators of the idea of cognitive unity, refer to abduction in their discussion of the process of generating conditional statements. They describe several different processes through which conditional statements might be generated, one of which involves abduction:

Generally speaking, a [process generating a condition, Type 4] consists in a reasoning which can be
described as follows: the regularity found in a particular generated case can put into action "expansive"
research of a "general rule" whose particular starting case was an example; during research, new cases
can be generated (cf. Pierce's "abduction"; see Arzarello et al. 1998[a]) (pp. 141-142)

Pedemonte (2001, 2002a,b, 2007, 2008) uses Peirce's theory of abduction to analyse the relationship between argumentation and proof. She adopts Arzarello's approach to abduction in combination with cognitive unity and uses Toulmin's (1958) model of argumentation to diagram the logical structure of an abduction. Pedemonte 
Table 2. Researchers' work placed in the framework for comparison of approaches to abductive reasoning in mathematics education

\begin{tabular}{|c|c|c|c|c|}
\hline \multirow{2}{*}{\multicolumn{2}{|c|}{ perspective, focus on... }} & \multicolumn{3}{|c|}{ the function of abductive reasoning } \\
\hline & & Discovery & Explanation & None specified \\
\hline \multirow{4}{*}{$\begin{array}{l}\text { logical } \\
\text { forms }\end{array}$} & $\begin{array}{c}\text { Peirce's logical form } \\
\text { of } 1878\end{array}$ & $\begin{array}{c}\text { Voigt (1984) } \\
\text { Arzarello \& Sabena (2011) }\end{array}$ & & $\begin{array}{c}\text { Arzarello, Micheletti, Olivero and } \\
\text { Robutti }(1998 a, b) \text {, Pedemonte (2002a) }\end{array}$ \\
\hline & $\begin{array}{l}\text { Peirce's logical form } \\
\text { of } 1903\end{array}$ & $\begin{array}{l}\text { Hoffmann (1999) } \\
\text { Meyer (2010) }\end{array}$ & $\begin{array}{l}\text { Hoffmann (1999) } \\
\text { Ferrando (2006) }\end{array}$ & Meyer (2010) \\
\hline & Eco's distinctions & & & \multirow[t]{2}{*}{ Pedemonte and Reid (2010) } \\
\hline & None specified & $\begin{array}{l}\text { Cifarelli \& Sáenz-Ludlow } \\
\text { (1996) }\end{array}$ & $\begin{array}{l}\text { Beck \& Jungwirth (1999), } \\
\text { Knipping (2002b) }\end{array}$ & \\
\hline
\end{tabular}

represents an abduction as an argument in which the claim and warrant are given, and the data is sought, consistent with Peirce's logical form of 1878, which she sometimes cites (e.g., in 2002a).

\section{ABDUCTIVE REASONING AS A PART OF PROVING}

Knipping (2003a,b) analyses abduction within the construction of an argument. The target conclusion of the argument is that a given quadrilateral is a square. The argument begins with a deduction from the given conditions that it is a rhombus. This is followed by an abduction, from the Result that it is a square, combined with the datum that it is a rhombus and a Rule (selected from the known properties of squares) that a rhombus with a right angle is a square, to imply the Case: it has a right angle. This Case then becomes the target of a new deductive argument. Once the Case has been proven deductively, the abduction is reversed, becoming a deduction of the desired conclusion, that the quadrilateral is a square.

Knipping is aware of the methodological work of Beck and Jungwirth, and Krummheuer, but she seems to adopt her conception of abduction from Pedemonte (see above). In Knipping's doctoral thesis (2003b) she does not cite anyone in relation to the case of abduction she describes. In describing the same case elsewhere (2003a) she cites Pedemonte (2002b).

\section{ABDUCTIVE REASONING AS PART OF A PROCESS LEADING TO DEDUCTION}

Meyer (2010) uses Peirce's later theory of abduction in his development of a theoretical framework for the analysis of discovery and verification processes in mathematics. Abduction is involved chiefly in discovery, in this framework, with deduction and induction being central in verification. This places give abductive reasoning a very different relationship to deductive than in Knipping's work (discussed in the previous section). For Mayer, abductive reasoning occurs before any deductive proving occurs. For Knipping, abductive reasoning occurs during proving.

While Meyer's main focus is on the exploratory function of abduction, he also notes its explanatory function, as well as making explicit the logical form of abduction he is applying. Meyer quotes the logical form Peirce stated explicitly in 1903, but he also distinguishes between two forms of abduction. Meyer's 'process of making an explanatory hypothesis plausible' has the logical form that he quoted from Peirce (1903), while 'flash of genius' has the form of Eco's creative abduction (implicit in Peirce, 1896). Meyer is also clearly aware of Peirce's early work, but focusses on his later work.

\section{A FRAMEWORK FOR COMPARISON OF APPROACHES}

Amid the increasing amount of mathematics education research that make use of Peirce's concept of abductive reasoning, it is sometimes difficult to locate relevant references, due to the differing approaches taken to using abduction in research. Here I outline a framework within which the research literature can be organised, and which I have already used above. The framework make first a distinction between two perspectives on abduction, one of which focusses on logical forms, and the other of which focusses on the function of abductive reasoning. While neither perspective denies the other, it is possible to quickly identify related research by observing if more attention is paid to logical forms or to functions.

\section{THE LOGICAL FORM OF THE REASONING}

Within the body of literature that attends to logical forms, it is further possible to make distinctions based on the precise forms that are used. For example, Arzarello, Micheletti, Olivero, and Robutti $(1998 \mathrm{a}, \mathrm{b})$ only reference Peirce's logical form of 1878: "inference of a case from a rule and a result" (p. 472; CP 2.623), while Meyer (2010) 
cites Peirce's logical form of 1903: "The surprising fact, C, is observed; But if A were true, C would be a matter of course, Hence, there is reason to suspect that A is true." (1903; CP 5.189). As noted above, these two logical forms can be read as being similar, but Meyer makes use of both possible readings of the 1903 logical form in his work, and so it is not surprising that he observes different types of abduction in analysing his data, types that might not have been observed by Arzarello, Micheletti, Olivero, and Robutti as they work with a more limited logical form. Pedemonte and Reid (2010) make use of several of Peirce's logical forms as well as Eco's distinctions between undercoded, overcoded and creative abductions, which allows them to make still finer distinctions in analysing their data. This is not to say that a more detailed categorisation of abductive reasoning is always needed or useful. Schurz (2008) offers almost a dozen subcategories of abduction, but that does not mean that mathematics educators studying abductive reasoning must make the same distinctions he does. For specific purposes a single logical form might be sufficient, and finer distinctions might be distracting. Readers of the literature, however, should be aware that researchers are making choices in which logical forms they use, and researchers should justify the choices they make.

\section{THE FUNCTIONS ADDRESSED BY REASONING}

Peirce himself came to see an excessive focus on logical forms as problematic, and so in his later work he focusses more on the functions of abduction to explain and to discover new facts and new rules. This perspective is shared by mathematics education researchers who are mainly concerned with abduction as a way of describing mathematical activity that explains and explores. It should be noted that this literature does not ignore logical forms altogether. Abduction is distinguished from deduction, and not all reasoning that allows students to explain or explore is automatically abductive. Deductive reasoning can also be used for exploration and explanation (de Villiers, 1990; Hanna, 2000). The distinction between the two functions of abduction allows one to identify researchers with different research objects and working in different traditions. For example, for Cifarelli (1999) abduction is important chiefly as a means of discovery in problem solving, but in the context of argumentation (e.g., in Knipping, 2002b) the explanatory function of an abduction can be more important.

\section{CONCLUSION}

In this chapter I have explored the origins of the concept of abductive reasoning, identified the most significant approaches in mathematics education literature that refers to abductive reasoning, and proposed a framework in which the different approaches taken in the research literature can be placed and compared. I trust this will be of use to readers of the mathematics education literature as they encounter the many variations in what exactly is referred to as 'abductive reasoning' in mathematics education.

\section{ENDNOTES}

1. References to the Collected Papers of Peirce (1960) are marked CP and indicate the volume number and paragraph number. The Collected Papers reorganises Peirce's work thematically, which means a single source might be split across several volumes and parts might be omitted. It also means that writings that Peirce composed at different times are sometimes juxtaposed, and this can lead to misunderstandings of his ideas. For this reason I have taken a chronological approach and wherever possible I include references to original sources.

2. In a manuscript written c. 1901 for Samuel P. Langley on Hume and miracles.

3. Die Abduktion besteht nun darin, eine neue allgemeine Regel zu konstruieren, mit der sich ein unerwartetes Ereignis oder ungeklärte Aspekte eines ansonsten bekannten Phänomens erklären lassen. Man versucht, probeweise neue Regeln zu formulieren, unter deren hypothetischer Gültigkeit das überraschende Ereignis plausibel wird.

4. Aus der Sicht der hier entfalteten semiotischen Lerntheorie taugen Darstellungs- und Zeichensysteme überhaupt nur dann als Instrumente des Lernens, wenn sie eine Regelhaftigkeit jenseits unserer subjektiven Bedingtheit aufweisen. Solche Regelhaftigkeit im Prozess diagrammatischen Schließens abduktiv zu erschließen, ist gemäß der hier skizzierten Theorie der Kern von Lernprozessen.

\section{REFERENCES}

Arzarello, F., \& Sabena, C. (2011). Semiotic and theoretic control in argumentation and proof activities. Educational Studies in Mathematics, 77(2-3), 189-206. https:/ / doi.org/10.1007/s10649-010-9280-3

Arzarello, F., Andriano, V., Olivero, F., \& Robutti, O. (1998). Abduction and conjecturing in mathematics. Philosophica, 61, 77-94. 
Arzarello, F., Micheletti, C., Olivero, F., \& Robutti, O. (1998a). A model for analysing the transition to formal proofs in geometry. In A. Olivier \& K. Newstead (Eds.), Proceedings of the Twentieth-second Annual Conference of the International Group for the Psychology of Mathematics Education (Vol. 2, pp. 24-31). Stellenbosch, South Africa.

Arzarello, F., Micheletti, C., Olivero, F., \& Robutti, O. (1998b). Dragging in Cabri and modalities of transition from conjectures to proofs in geometry. In A. Olivier \& K. Newstead (Eds.), Proceedings of the Twentieth-second Annual Conference of the International Group for the Psychology of Mathematics Education (Vol. 2 pp. 32-39). Stellenbosch, South Africa.

Arzarello, F., Olivero, F., Paola, D., \& Robutti, O. (2002). A cognitive analysis of dragging practices in Cabri environments. ZDM: The International Journal on Mathematics Education, 34(3), 66-72.

Beck, C., \& Jungwirth, H. (1999). Deutungshypothesen in der interpretativen Forschung. Journal für MathematikDidaktik, 20(4), 231-259. https:/ / doi.org/10.1007/BF03338900

Boero, P., Garuti, R., \& Lemut, E. (1999). About the generation of conditionality of statements and its links with proving. In O. Zaslavsky (Ed.) Proceedings of the 23rd Conference of the International Group for the Psychology of Mathematics Education (Vol. 2, pp. 137-144), Haifa, Israel:PME.

Boero, P., Garuti, R., Lemut, E., \& Mariotti M. A. (1996). Challenging the traditional school approach to theorems: A hypothesis about the cognitive unity of theorems. In L. Puig \& A. Gutierrez (Eds.), Proceedings of the Twentieth Conference of the International Group for the Psychology of Mathematics Education (Vol. 2, pp. 113-120). Valencia, Spain: PME.

Bonfantini, M. \& Proni, G. (1983). To guess or not to guess. In U. Eco \& T. Sebeok (Eds.). The sign of three: Dupin, Holmes, Peirce, (pp. 119-134). Bloomington, IN: Indiana University Press.

Brandt, B., \& Krummheuer, G. (2000). Das Prinzip der Komparation im Rahmen der Interpretativen Unterrichtsforschung in der Mathematikdidaktik. In Journal for Mathematik-didaktik, 21(3/4), 193-226. https:/ / doi.org/10.1007/BF03338919

Cifarelli, V. \& Sáenz-Ludlow, A. (1996). Abductive processes and mathematics learning. In E. Jakubowski, D. Watkins, \& H. Biske (Eds.), Proceedings of the Eighteenth Annual Meeting of the North American Chapter of the International Group for the Psychology of Mathematics Education (Vol. I, pp. 161-166). Columbus, OH: ERIC Clearinghouse for Science, Mathematics, and Environmental Education.

Cifarelli, V. (1997b). Emergence of novel problem solving activity. In E. Pehkonen (Ed.) Proceedings of the 21st Conference for the International Group for the Psychology of Mathematics Education (Vol. 2, pp. 145-152). Lahti, Finland: University of Helsinki and Lahti Research and Training Center.

Cifarelli, V. (1999). Abductive Inference: Connections between Problem Posing and Solving. In O. Zaslavsky (Ed.) Proceedings of the 23rd Conference of the International Group for the Psychology of Mathematics Education (Vol. 2, pp. 217-224). Haifa: PME.

Cifarelli, V. V. (1997a, March). Emergence of abductive reasoning in mathematical problem solving. Paper presented to the Special Interest Group for Research in Mathematics Education at the annual conference of the American Educational Research Association, Chicago, Illinois.

de Villiers, M. (1990). The role and function of proof in mathematics. Pythagoras, 24, 17-24.

Eco, U. (1983). Horns, hooves, insteps: Some hypotheses on three types of abduction. In U. Eco \& T. Sebeok (Eds.), The sign of three: Dupin, Holmes, Peirce, (pp. 198-220). Bloomington, IN: Indiana University Press.

Fann K. T. (1970). Peirce's theory of abduction. The Hague, Holland: Martinus Nijhoff. https:/ / doi.org/10.1007/97894-010-3163-9

Ferrando, E. (2000). The relevance of Peircean theory of abduction to the development of students' conceptions of proof (with particular attention to proof in calculus). In C. W. Spinks \& S. Simpkins (Eds.), Proceedings of the twenty-fourth annual meeting of the Semiotics Society of America: Semiotics 2000 (pp. 1-16). New York: Legas.

Ferrando, E. (2006). The abductive system. In Novotná, J., Moraová, H., Krátká, M. \& Stehlíková, N. (Eds.), Proceedings of the Thirtieth Conference of the International Group for the Psychology of Mathematics Education (Vol. 3, pp. 57-64). Prague, Czech Republic.

Habermas, J. (1968). Erkenntnis und Interesse. Suhrkamp, Frankfurt am Main 1968.

Habermas, J. (1987). Knowledge and human interests. Translated by Jeremy J. Shapiro. Cambridge UK: Polity.

Hanna, G. (2000). Proof, explanation and exploration: An overview. Educational Studies in Mathematics, 44(1\&2), 523. https:// doi.org/10.1023/A:1012737223465

Hoffmann, M. H. G. (1999). Problems with Peirce's concept of abduction. Foundations of Science, 4(3), 271-305. https://doi.org/10.1023/A:1009675824079 
Hoffmann, M. H. G. (2001). Skizze einer semiotischen Theorie des Lernens. Journal für Mathematik-Didaktik, 22(3-4), 231-251. https:// doi.org/10.1007/BF03338937

Knipping, C. (2003a). Argumentation structures in classroom proving situations. In M.A. Mariotti (Ed.), Proceedings of the Third Conference of the European Society in Mathematics Education (unpaginated). Bellaria, Italy. Retrieved from http:/ / ermeweb.free.fr/CERME3/Groups/TG4/TG4_Knipping_cerme3.pdf

Knipping, C. (2003b). Beweisprozesse in der Unterrichtspraxis: Vergleichende Analysen von Mathematikunterricht in Deutschland und Frankreich [Proving processes in teaching practices - Comparative analysis of mathematics teaching in France and Germany]. Hildesheim: Franzbecker Verlag.

Krummheuer, G. (2007). Argumentation and participation in the primary mathematics classroom: Two episodes and related theoretical abductions. Journal of Mathematical Behavior, 26(1), 60-82. https://doi.org/10.1016/j.jmathb.2007.02.001

Magnani, L. (2001). Abduction, reason and science: Processes of discovery and explanation. Dordrecht: Kluwer Academic Publishers. https:/ / doi.org/10.1007/978-1-4419-8562-0

Meyer, M. (2010). Abduction - A logical view for investigating and initiating processes of discovering mathematical coherences. Educational Studies in Mathematics, 74(2), 185-205. https:/ / doi.org/10.1007/s10649-010-9233-x

Pedemonte, B. (2001). Some cognitive aspects of the relationship between argumentation and proof in mathematics. In M. van den Heuvel-Panhuizen (Ed.), Proceedings of the 25th Conference of the International Group for the Psychology of Mathematics Education (Vol. 4, pp. 33-40). Utrecht: PME.

Pedemonte, B. (2002a). Etude didactique et cognitive des rapports de l'argumentation et de la démonstration dans l'apprentissage des mathématiques. Thèse de doctorat. Grenoble I: Université Joseph Fourier.

Pedemonte, B. (2002b). Relation between argumentation and proof in mathematics: cognitive unity or break? In J. Novotná (Ed.), Proceedings of the 2nd Conference of the European Society for Research in Mathematics Education (pp. 70-80). Marienbad.

Pedemonte, B. (2007). How can the relationship between argumentation and proof be analysed? Educational Studies in Mathematics, 66, 23-41.

Pedemonte, B. (2008). Argumentation and algebraic proof. ZDM - The International Journal on Mathematics Education, 40(3), 385-400. https:// doi.org/10.1007/s11858-008-0085-0

Pedemonte, B., \& Reid, D. (2011). The role of abduction in proving processes. Educational Studies in Mathematics, 76(3), 281-303. https:/ / doi.org/10.1007/s10649-010-9275-0

Peirce, C. S. (1867). On the natural classification of arguments. Presented 9 April 1867 to the American Academy of Arts and Sciences. Proceedings of the American Academy of Arts and Sciences 7, 261-287. (Compiled in Peirce, C. S., 1960, 2.461-516).

Peirce, C. S. (1878). Deduction, induction, and hypothesis. Popular Science Monthly, 13 (August), 470-82. (Compiled in Peirce, C. S., 1960, 2.619-644)

Peirce, C. S. (1883). A Theory of Probable Inference, in C. S. Peirce (Ed.) Studies in Logic, pp. 126-181. Boston: Little, Brown and Co. (Compiled in Peirce, C. S., 1960, 2.694-754) https:/ / doi.org/10.1037/12811-007

Peirce, C. S. (1896). manuscript "The Logic of Mathematics; an Attempt to Develop my Categories from within." (Compiled in Peirce, C. S., 1960, CP 1.417-520).

Peirce, C. S. (1902a). The Carnegie Application. (Compiled in Peirce, C. S., Writings, Vol 4, p. 588) Arisbe homepage: http://www.door.net/arisbe/menu/library/bycsp/ L75/L75.htm.

Peirce, C. S. (1902b). Minute Logic, an uncompleted book. (Compiled in Peirce, C. S., 1960, in various places including 2.102)

Peirce, C. S. (1903) Lectures on Pragmatism (held from March, 26. to May, 14. at Harvard University). (Compiled in Peirce, C. S., 1960, 5.14-212)

Peirce, C. S. (1960). Collected papers. Cambridge, MA: Harvard University Press.

Rivera, F. D., \& Becker, J. R. (2007). Abduction-induction (generalization) processes of elementary majors on figural patterns in algebra. The Journal of Mathematical Behavior, 26(2), 140-155. https:// doi.org/10.1016/j.jmathb.2007.05.001

Saenz-Ludlow, A. (1997). Inferential processes in Michael's mathematical thinking. In E. Pehkonen (Ed.) Proceedings of the 21st Conference for the International Group for the Psychology of Mathematics Education (Vol. 4, 169-176). Lahti, Finland: University of Helsinki and Lahti Research and Training Center.

Schurz, G. (2008). Patterns of abduction. Synthese, 164(2), 201-234. https:/ / doi.org/10.1007/s11229-007-9223-4

Toulmin, S. E. (1958). The uses of argument, Cambridge, UK: Cambridge University Press. 
Voigt, J. (1984). Interaktionsmuster und Routinen im Mathematikunterricht. Theoretische Grundlagen und mikroethnographische Falluntersuchungen ["Interaction patterns and routines in instructing. Theoretical basics and microethnographical case studies"]. Weinheim: Beltz.

Voigt, J. (2000). Abduktion. In M. Neubrand (Ed.) Beitrage zum Mathematikunterricht. Vortrage auf der 34. Tagungfiir Didaktik der Mathematik vom 28. Februar bis 3. Marz 2000 in Potsdam. pp. 694-697. Hildesheim: Franzbecker.

Weber, K., Maher, C., Powell, A., \& Lee, H. S. (2008). Learning opportunities from group discussions: Warrants become the objects of debate. Educational Studies in Mathematics, 68(3), 247-261. https://doi.org/10.1007/s10649-008-9114-8

\section{http://www.ejmste.com}

